\title{
Dynamic Spillover Between The Oil And Stock Markets Of Emerging Oil-Exporting Countries
}

Frederic Teulon, IPAG Business School, France

Khaled Guesmi, IPAG Business School \& EconomiX - University of Paris Ouest Nanterre La Défense, France

\begin{abstract}
The paper investigates the time-varying correlations between stock market returns and oil prices in oil-exporting countries. A multivariate GARCH-DCC process is employed to evaluate this relationship based on data from Venezuela, the United Arab Emirates, Saudi Arabia and Kuwait. The results show that there are time-varying correlations between the oil and stock markets in emerging, oil-producing countries, indicating that they are affected by conditions in world markets. In addition, the relationship between oil prices and stock returns is found to be influenced by the origin of shocks to oil prices, with stock market responses being stronger to demand-side shocks caused by political turmoil or fluctuations in the global business cycle than to supply-side shocks caused by cuts in oil production. The results also provide evidence of volatility spillovers between the oil and stock markets.
\end{abstract}

Keywords: Time-Varying Integration; Oil Exporting Countries; Oil Market

\section{INTRODUCTION}

( $\mathrm{n}$ recent years, much empirical research has focused on the impact of oil prices on macroeconomic variables in developed countries (Kilian \& Park, 2009). Among such studies, attention is increasingly being devoted to the correlation between oil prices and stock markets. Although there is no theoretical model that describes the relationship between the oil and financial markets, academic research finds that fluctuations in oil prices affect corporate performance, output, and earnings, which subsequently influence stock returns.

Most existing studies focus on the relationship between the oil and financial markets in oil-importing countries, such as the United States (US), where increases in oil prices have negative economic effects. When oil prices increase, oil importers can experience strong negative consequences and economic recession (Ferderer, 1996). However, the effects of changes in oil prices on other sets of countries are worth investigating. For this reason, the paper addresses the relationship between oil prices and financial markets from the perspective of emerging, oilexporting countries.

The relationship between oil prices and financial markets is thought to have specific effects on members of the Organization of the Petroleum Exporting Countries (OPEC). In contrast to the case of oil importers, increases in oil prices positively influence the economies of oil-exporting countries by providing them with additional income and wealth. If this surplus income is transmitted back to the economy, then higher oil prices would be expected to lead to both higher levels of economic activity and higher stock prices. On the other hand, decreases in oil prices have a negative relationship with the economic growth of oil producers and can generate political and social instability (Yang et al., 2002), putting downward pressure of financial returns. Therefore, as underlined by Bashar (2006) and Arouri et al. (2010), the relationship between stock markets and oil prices in oil-exporting countries can be ambiguous and needs to be investigated.

In addition to the study of co-movements, another relevant research area is volatility analysis. The most recent literature on this subject focuses on volatility spillovers between oil or industrial commodities and stock 
markets. Hammoudeh et al. (2004) investigate the spillover effects, day effects, and dynamic relationships (among the daily prices of five S\&P 500 oil sector stocks and the prices of five types of oil in the US oil market) using cointegration techniques as well as ARCH-type models. The authors find evidence of volatility spillovers from the oil futures market to some oil stocks. Chiou and Lee (2009) examine the daily asymmetric effects of WTI oil prices on S\&P 500 stock returns. Using the Autoregressive Conditional Jump Intensity model with expected, unexpected, and negative unexpected oil price fluctuations, they find that high fluctuations in oil prices have unexpected, asymmetric effects on stock returns. Malik and Ewing (2009) rely on bivariate GARCH models to estimate the transmission of volatility between weekly WTI oil prices and equity returns, finding evidence of spillover mechanisms. Choi and Hammoudeh (2010) extend the time-varying correlations analysis by examining prices of commodities including Brent oil, WTI oil, copper, gold, and silver in relation to the S\&P 500 index. They show that correlations between commodity prices have increased since 2003, limiting portfolio hedging substitutability. More recently, Arouri et al. (2010) examine the relation between oil prices and 12 stock markets in European countries. Their results show that the reactions of returns to changes in oil prices vary considerably across industrial sectors; furthermore, the inclusion of oil assets into a portfolio of stocks allows for improvements in the portfolio's riskreturn characteristics. Of particular interest for our study is the work of Filis et al. (2011) who analyze time-varying correlations between Brent oil prices and stock markets by differentiating between oil-importing and oil-exporting countries. They find that time-varying correlations depend on the origins of oil shocks; responses are much greater to aggregate-demand-side shocks than to supply-side shocks originating from cuts in OPEC production.

In order to better understand these issues, this study evaluates oil and stock market interdependence in oilexporting countries by measuring interactions between oil prices and stock market indices as per the correlation analysis defined by Engle (2002). The remainder of this paper is organized as follows: Section 2 presents the empirical methodology, the data are described in Section 3, the results are reported and discussed in Section 4, and Section 5 concludes.

\section{METHODOLOGY}

In this research, we apply time-varying correlation coefficients estimated from a multi-variate GARCHDCC model introduced by Engle (2002).

By allowing conditional correlations to vary over time, his specification is viewed as a generalization of the Constant Conditional Correlation (CCC) model (Bollerslev, 1990). To illustrate the dynamic conditional correlation model for our purposes, let $x_{t}$ be a $6 \times 1$ vector (four stock markets, world market and oil prices) containing return, volume, and implied volatility series in the following conditional mean equation:

$x_{\mathrm{t}}=\mu_{\mathrm{t}}+\varepsilon_{\mathrm{t}}$

where $\mu_{t}=E\left[x_{t} \| \Pi_{t-1}\right]$ is the conditional expectation of $x_{t}$ given the past information $\Pi_{t-1}$, and $\varepsilon_{t}$ is a vector of errors in autoregression $\mathrm{AR}(1)$.

Assuming that the return, volume and implied volatility series $x_{t}$ are determined by the information set available at time $\mathrm{t}-1$, the model may be estimated using maximum likelihood methods, provided the conditional covariance matrix, $H_{\mathbf{t}}$. We also assume that $\mu_{\mathbf{t}}$ takes the following form:

$\mu_{i, t}=\Phi_{0}+\Phi_{1} x_{i, t-1}, \forall \mathrm{i}$

$\Phi_{1}$ measures the ARCH effect in data series. In the traditional multivariate GARCH framework, the conditional variance-covariance matrix can be written as:

$H_{t}=G_{t} R_{t} G_{t}$ where $G_{t}=\operatorname{diag}\left\{\sqrt{h_{i t}}\right\}$ 
$h_{i t}$ is the estimated conditional variance from the individual standard univariate $\operatorname{GARCH}(1,1)$ models in the following manner:

$$
h_{i t}=\omega_{i}+\alpha_{i} \varepsilon_{i, t-1}^{2}+\beta_{i} h_{i, t-1} \quad \forall i
$$

$R_{t}$ is the time-varying conditional correlation coefficient matrix. As specified in Equation (4), the variance of each market is modeled as a function of the constant, the square of the last period's own residuals $\varepsilon_{i, t-1}^{2}$, and its lagged conditional variance $h_{i, t-1}$. After the basic construction delineated above, the dynamic correlation coefficient matrix of the DCC model can be denoted by:

$$
\begin{aligned}
& R_{t}=\left[\operatorname{diag}\left(Q_{t}\right)\right]^{\frac{1}{2}} Q_{t}\left[\operatorname{diag}\left(Q_{t}\right)\right]^{-\frac{1}{2}} \\
& Q_{t}=\left(q_{i j, t}\right) \\
& {\left[\operatorname{diag}\left(Q_{t}\right)\right]^{-\frac{1}{2}}=\operatorname{diag}\left(\frac{1}{\sqrt{q_{11, t}}}, \frac{1}{\sqrt{q_{22, t}}}, \ldots \frac{1}{\sqrt{q_{12,12, t}}}\right)}
\end{aligned}
$$

In order to standardize the residual error term, Engle sets $w_{t}=G_{t}^{-1} \varepsilon_{t}$ where $G_{t}$ is a $6 \times 6$ diagonal matrix of conditional standard deviations and $z_{t}$ is the standardized residuals vector with a mean of zero and variance of one. Engle also suggests the estimation of the following time-varying correlation process:

$$
\rho_{i j, t}=\frac{q_{i j, t}}{\sqrt{q_{i i, t} q_{j j, t}}}
$$

where

$$
q_{i j, t}=\bar{\rho}_{i j}+a\left(z_{i, t-1} z_{j, t-1}-\bar{\rho}_{i j}\right)+b\left(q_{i j, t-1}-\bar{\rho}_{i j}\right)=(1-a-b) \bar{\rho}_{i j}+a z_{i, t-1} z_{j, t-1}+b q_{i j, t-1}
$$

The time-varying correlation coefficients in GARCH-DCC model can be divided into two components. The first component, $\bar{\rho}_{i j}$, on the right-hand side of Equation (6) represents the unconditional expectation of the cross product $z_{i t} z_{j t}$; i.e., the unconditional correlation coefficient. The second component, $a z_{i, t-1} z_{j, t-1}+b q_{i j, t-1}$, also on the right-hand side of Equation (6), indicates the conditional time-varying covariance.

\section{DATA AND STOCHASTIC PROPERTIES}

\subsection{Description of the Data}

The data sources for our study are Datastream International, MSCI, and the International Monetary Fund's (IMF) International Financial Statistics databases. We used monthly data collected from the stock market indices of oil-exporting countries (Venezuela, the United Arab Emirates, Saudi Arabia, and Kuwait), a world stock market index (WORLD), and Brent crude oil index (OIL) over the period August 31, 2000 to June 31, 2010. All returns are expressed in US dollars (USD). 


\subsection{Main Statistics and Stochastic Properties}

Table 1 reports the main statistics of the return series for the stock market and Brent crude oil indices. All the series depart from conditions of normality and conditional heteroskedasticity. The market of the United Arab Emirates was the most volatile during the studied period in terms of standard deviation $(12.67 \%)$, while that of Kuwait was the least volatile (5.96\%). The skewness coefficients are positive for the United Arab Emirates and Venezuela. They are significantly different from zero for almost all markets, indicating the presence of asymmetry in the distribution of returns. In addition, all the return series are characterized by a kurtosis coefficient that is statistically significant and greater than three, meaning that they have fatter tails than those of a normal distribution.

Engle's (1982) test for the first order of conditional heteroskedasticity is also performed and the hypothesis of no ARCH effects for all considered return series cannot be rejected. This result motivates our choice of the GARCH modeling approach for conditional variance processes.

Table 1: Descriptive Statistics of Return Series

\begin{tabular}{|l|c|c|c|c|c|}
\hline Panel B: Excess Returns On Stock Market Indices & \multicolumn{4}{l|}{ Kurtosis } & ARCH(1) \\
\hline & Mean & Std. Dev. & Skewness & Kur \\
\hline United Arab Emirates & 0.013107 & 0.126709 & 0.118074 & 3.354331 & $17.145^{++}$ \\
\hline Kuwait & 0.015864 & 0.059667 & -0.284409 & 3.587228 & $24.044^{+++}$ \\
\hline Saudi Arabia & 0.008233 & 0.083340 & -0.822876 & 4.298505 & $23.696^{+++}$ \\
\hline Venezuela & 0.018655 & 0.083850 & 0.449107 & 6.660345 & $17.174^{+++}$ \\
\hline World & 0.000571 & 0.061376 & -0.867876 & 7.874304 & $20.294^{+++}$ \\
\hline Oil Prices & 0.008252 & 0.096485 & -1.093871 & 4.273078 & $23.766^{+++}$ \\
\hline
\end{tabular}

Notes: ARCH(1) is the empirical statistics of the Engle (1982)'s test for the $6^{\text {th }}$ order of ARCH effects. ${ }^{+},{ }^{++}$, and ${ }^{+++}$indicate that the null hypothesis of no ARCH effects is rejected at the $10 \%, 5 \%$ and $1 \%$ levels respectively.

The highest correlation is observed for the pair, including the United Arab Emirates and Kuwait (0.28) (see Table 2). The stock market of the United Arab Emirates has the lowest unconditional correlation with the world market (-0.13). The correlations of the Kuwaiti and Saudi markets with the world market are -0.04 and -0.06 , respectively. We also notice a negative correlation between stock returns in the United Arab Emirates and the real exchange rate returns in Kuwait (-0.03), which is consistent with the view that the foreign exchange market in the United Arab Emirates may serve as a hedge against risks in the Kuwaiti stock market during bear market periods.

\begin{tabular}{|c|c|c|c|c|c|c|}
\hline & RE EU & RE KU & RE SA & RE VE & RF $\mathbf{W}$ & RF OI \\
\hline RE EU & 1,00 & 0,29 & $0, \overline{42}$ & $-0,18$ & $-0,13$ & $-0,13$ \\
\hline RE KU & 0,29 & 1,00 & 0,28 & $-0,05$ & $-0,04$ & $-0,09$ \\
\hline RE SA & 0,42 & 0,28 & 1,00 & 0,08 & $-0,06$ & $-0,11$ \\
\hline RE VE & $-0,18$ & $-0,05$ & 0,08 & 1,00 & 0,03 & $-0,13$ \\
\hline RE W & $-0,13$ & $-0,04$ & $-0,06$ & 0,03 & 1,00 & 0,12 \\
\hline RE OI & $-0,13$ & $-0,09$ & $-0,11$ & $-0,13$ & 0,12 & 1,00 \\
\hline
\end{tabular}

Notes: DU, SA, KU, VE, W, US and OI identify the stock market of U. A. Emirates, Saudi Arabia, Kuwait, Venezuela, World and Oil prices. ARCH(6) is the empirical statistics of the Engle (1982)'s test for the $6^{\text {th }}$ order of ARCH effects. ${ }^{+},{ }^{++}$, and ${ }^{+++}$indicate that the null hypothesis of no ARCH effects is rejected at the $10 \%, 5 \%$ and $1 \%$ levels respectively.

Table 3 shows the autocorrelations and partial autocorrelations of excess returns on stock markets and Brent crude oil indices, as well as returns on real exchange rates. Particularly noteworthy is that only first-order autocorrelations are significant at the $1 \%$ level for stock returns, oil prices, and exchange rates. This finding suggests that the $\mathrm{GARCH}(1,1)$ parameterization for second moments is appropriate. 
Table 3: Autocorrelations of Return Series Panel A: Autocorrelations of Excess Returns on Stock Market Indices and Oil Prices

\begin{tabular}{|l|c|c|c|c|c|c|c|c|c|c|}
\hline \multirow{2}{*}{ Lag } & \multicolumn{2}{|c|}{ Oil Prices } & \multicolumn{2}{c|}{ U. A. Emiraties } & \multicolumn{2}{c|}{ Kuwait } & \multicolumn{2}{c|}{ Saudia Arabia } & \multicolumn{2}{c|}{ Venezuela } \\
\cline { 2 - 11 } & $\mathbf{A C}$ & PAC & AC & PAC & AC & PAC & AC & PAC & AC & PAC \\
\hline 1 & $0.095^{* * *}$ & $0.048^{* * *}$ & $0.185^{* * *}$ & $0.185^{* * *}$ & $0.134^{* * *}$ & $0.134^{* * *}$ & $0.174^{* * *}$ & $0.174^{* * *}$ & $0.147^{* * *}$ & $0.147^{* * *}$ \\
\hline 2 & 0.049 & 0.019 & 0.415 & 0.394 & 0.137 & 0.122 & 0.180 & 0.154 & 0.056 & 0.035 \\
\hline 3 & -0.059 & -0.083 & 0.139 & 0.024 & -0.074 & -0.110 & 0.122 & 0.073 & 0.101 & 0.090 \\
\hline 4 & -0.029 & -0.004 & 0.262 & 0.100 & 0.147 & 0.160 & 0.128 & 0.077 & 0.106 & 0.080 \\
\hline 5 & -0.240 & -0.239 & 0.140 & 0.050 & 0.102 & 0.092 & 0.111 & 0.057 & 0.153 & 0.125 \\
\hline 6 & 0.223 & 0.223 & 0.177 & 0.029 & 0.116 & 0.044 & 0.074 & 0.015 & 0.038 & -0.012 \\
\hline
\end{tabular}

Notes: This table reports the serial correlation and partial autocorrelation functions for excess stock market returns. ${ }^{* *}$ and ${ }^{* * *}$ indicate the significance at the $5 \%$ and $1 \%$ levels respectively.

\section{EMPIRICAL RESULTS}

Table 4 shows that the average dynamic conditional correlation between stock markets and oil prices is positive and significant at the $1 \%$ level, thus providing evidence of volatility spillovers between oil and stock markets. However, this is not the case for Venezuela, whose dynamic correlations are not significant, probably because of the very limited development of its stock market compared to the importance of oil in that economy (World Bank, 2012).

Table 4: Dynamic Conditional Correlations between Stock Markets and the World Market

\begin{tabular}{|l|c|c|c|c|}
\hline & United Arab Emirates & Kuwait & Saudi Arabia & Venezuela \\
\hline$\rho \max$ & 0.128 & 0.005 & -0.094 & 0.045 \\
\hline$\rho \min$ & -0.178 & -0.038 & -0.129 & -0.011 \\
\hline$\rho$ mean & $-0.151^{* * *}$ & $-0.017^{*}$ & $-0.110^{* * *}$ & $-0.020^{*}$ \\
\hline Std. dev. & 0.011 & 0.011 & 0.008 & 0.013 \\
\hline
\end{tabular}

Notes: This table reports some statistics of dynamic conditional correlations, estimated from the DCC-GARCH model. $\rho$ max, $\rho$ min, and $\rho$ mean indicate the maximum, minimum and average values of dynamic conditional correlations. ${ }^{*},{ }^{* *}$, and ${ }^{* * *}$ indicate that the average degree of integration is significantly different from zero at the $10 \%, 5 \%$, and $1 \%$ levels with respect to the two-sided Student-t test, respectively.

As Figure 1 illustrates, correlations increase starting from the end of 2007 in the cases of the United Arab Emirates, Kuwait, and Saudi Arabia. These countries display positive correlations during all the investigated periods and exhibit considerable decreases in correlation coefficients between 2000 and 2004. This period is characterized by changes in the precautionary demand for crude oil as a result of the Iraq war (see Filis et al., 2011). Our results are consistent with those of Forbes and Rigobon (2002) who stressed that increased correlations during times of crisis are caused by increased volatility in global stock markets.
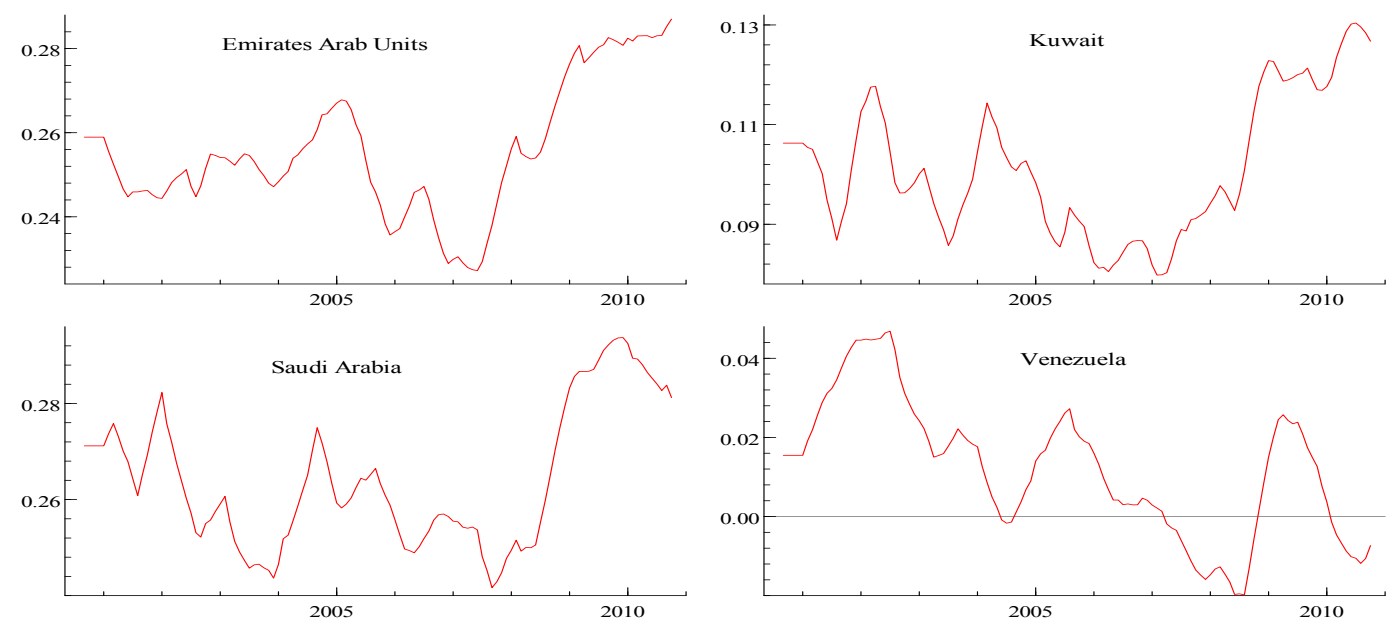

Figure 1: Dynamic Conditional Correlations with Oil Note: The unit is the correlation coefficient 
The next sub-period of interest is from 2006 to 2008, when oil prices increased significantly (except in Venezuela) due to rising demand, mainly from China. The correlation coefficient showed an increasing and positive pattern for all countries. This aggregate-demand-side oil price shock is expected to have a positive effect on stock markets because it signals an increase in world trade. This finding is in line with Hamilton (2009) and Kilian and Park (2009), who suggested that aggregate-demand-side oil price shocks resulting from global economic growth have a positive impact on stock prices.

Two main conclusions can be drawn from our investigation. Oil price shocks during periods of global turmoil and political instability have an important impact on the relationship between oil prices and stock market returns. Regarding the sign of this correlation, we find two trends - a negative one, in the case of Venezuela between 2007 and 2009, and a positive one, when aggregate-demand-side oil price shocks (Asian crisis, Chinese economic growth, and the global financial crisis) result in a significant positive correlation between stock market and oil prices. The repercussions of these phenomena are not symmetric in all the studied countries; therefore, we do not see a proper "contagion effect". However, some specific trends appear among countries whose stock markets exhibit positive correlations.

\section{CONCLUSION}

The current study investigates time-varying correlations between stock market returns and oil prices in oilexporting countries, considering the origin of shocks to oil prices (i.e., aggregate-demand-side, precautionary demand, or supply-side). The dataset consists of monthly stock and oil prices from the major oil-exporting countries - Venezuela, the United Arab Emirates, Saudi Arabia, and Kuwait - from August 31, 2000 to Jun 31, 2010.

Conditional correlations are estimated following the GARCH-DCC method of Engle (2002). The study provides evidence for time-varying correlations between oil and stock prices. The results show a significant increase in the mean of the dynamic conditional correlation coefficient between world and the examined emerging, oilexporting countries.

Furthermore, the correlation is found to change as a result of the origin of shocks to oil prices stemming from periods of global turmoil or changes in the global business cycle. In particular, precautionary demand shocks, caused by wars or terrorist attacks, and aggregate-demand-side shocks, caused by fluctuations in the global business cycle (i.e., housing market boom, Chinese growth, global financial crisis), tend to influence the correlation between oil and stock market prices to a much greater extent than supply-side shocks originating from OPEC production cuts.

\section{AUTHOR INFORMATION}

Frédéric Teulon is Head of the Research center (IPAG research Lab) and made a career as a professor at various universities in Paris. He now teaches at the IPAG Business School. His main research areas are macroeconomics and international finance. E-mail: f.teulon@ipag.fr

Khaled Guesmi is Professor at the IPAG Business School and is a specialist in quantitative studies. His main research areas are quantitative finance and econometrics. E-mail: khaled.guesmi@ipag.fr (Corresponding author)

\section{REFERENCES}

1. Arouri, M. E. H., \& Nguyen, D. K. (2010). Oil prices, stock markets and portfolio investment: Evidence from sector analysis in Europe over the last decade. Energy Policy, 38, 4528-4539.

2. Bashar, A. Z. (2006). Wild oil prices, but brave stock markets! The case of GCC stock markets. Operational Research, 6(2), 145-162.

3. Bollerslev, T. (1990). Modelling the coherence in short-run nominal exchange rates: A multivariate generalized ARCH model. Review of Economics and Statistics, 72, 498-505.

4. Chiou, J. S., \& Lee, Y. H. (2009). Jump dynamics and volatility: Oil and the stock markets. Energy, 34(6), 788-796. 
5. Choi, K., \& Hammoudeh, S. (2010). Volatility behavior of oil, industrial commodity and stock markets in a regime-switching environment. Energy Policy, 38(8), 4388-4399.

6. Engle, R. (1982). Autoregressive conditional heteroskedasticity with estimates of the variance of U.K Inflation. Econometrica, 50, 987-1008.

7. Engle, R. F. (2002). Dynamic conditional correlation: A simple class of multivariate generalized autoregressive conditional heteroskedasticity models. Journal of Business and Economic Statistics, 20, $339-350$.

8. Federer, J. P. (1996). Oil price volatility and the macroeconomy. Journal of Macroeconomics, Winter 1996, $18(1)$, pp. 1-26.

9. Filis, G., Degiannakis, S., \& Floros, C. (2011). Dynamic correlation between stock market and oil prices: The case of oil-importing and oil-exporting countries. International Review of Financial Analysis, 20(3), 152-164.

10. Forbes, K. \& Rigobon R. (2001). No contagion, only interdependence: measuring stock market comovements. NBER Working Paper 7267.

11. Hamilton, D. J. (2009). Causes and consequences of the oil shock of 2007-08. Brooking papers on economic activity, spring, 215-261.

12. Hammoudeh, S., Dibooglu, S., \& Aleisa, E. (2004). Relationships among U.S. oil prices and oil industry equity indices. International Review of Economics and Finance, 13(4), 427-453.

13. Kilian, L., \& Park, C. (2009). The impact of oil price shocks on the U.S market. International Economic Review, 50, 1267-1287.

14. Malik, F., \& Ewing, B. T. (2009). Volatility transmission between oil prices and equity sector returns. International Review of Financial Analysis, 18, 95-100.

15. Yang, C. W., Hwang, M. J., \& Huang, B.N. (2002), An analysis of factors affecting price volatility of the US oil market. Energy Economics, 24, 107-119. 


\section{NOTES}

